\title{
DIMENSIONAMENTO DO ESTOQUE DE DERIVADOS DE SANGUE EM UM HEMOCENTRO DO BRASIL BASEADO EM UM MODELO DE GESTÃO DE ESTOQUES E PREVISÃO DE DEMANDA
}

\section{SIZING INVENTORY OF BLOOD PRODUCTS IN A BLOOD BANK AT BRAZIL BASED ON A MODEL OF INVENTORY MANAGEMENT AND A DEMAND FORECAST}

\author{
Julia Lorena Marques Gurgel* E-mail: lorena.ufersa@gmail.com \\ Breno Barros Telles do Carmo** E-mail: brenotelles@hotmail.com \\ *Universidade Estadual do Rio Grande do Norte (UERN), Mossoró, RN \\ **Universidade Federal Rural do Semi Árido (UFERSA), Mossoró, RN
}

\begin{abstract}
Resumo: O gerenciamento dos estoques dos produtos oriundos do processamento do sangue coletado nos hemocentros é um problema para os serviços de saúde do Brasil e do mundo. Dimensionar os estoques destes produtos de forma a equalizar a demanda e oferta não é uma tarefa simples. É necessário assegurar que o produto esteja disponível quando for preciso e em tempo hábil. Contudo, não se pode superdimensionar estes estoques dado que o produto é perecível e que a disponibilidade da matéria prima (sangue) para o processamento não é abundante. Existem poucos estudos no Brasil, entretanto, que discutem essa questão. Este estudo focará um hemocentro brasileiro, que tem enfrentado o desafio de dimensionar a demanda pelos produtos hemoterápicos e estabelecer parâmetros de controle de seus estoques. O objetivo desta pesquisa é adaptar um estudo recente realizado fora do país, sobre dimensionamento de estoques de um inventário para bancos de sangue, aliado a um modelo de previsão de demanda por hemocomponentes subclassificados em tipo sanguíneo. Esse controle visa aumentar a disponibilidade do serviço de hemoterapia, à medida que pretende diminuir a escassez e o desperdício do sangue coletado. Dessa forma, observou-se que o modelo de gestão de estoques se adequou a alguns casos.
\end{abstract}

Palavras-chave: Hemocentro. Previsão de Demanda. Gerenciamento de estoques. Hemocomponentes.

\begin{abstract}
The management of the stocks of products derived from the blood processing collected in blood banks is a problem for health services in Brazil and the world. Quantify the stocks of these products in order to equalize the demand and supply is not a simple task. It's necessary ensure that the product is available when needed and in due time. However, there is no how overestimate these stocks given that the product is perishable and it is not easy the availability of raw material (blood) for processing. There are few studies in Brazil, however, that discuss this issue. This study will focus on one Brazilian Hemocentro, which has faced the challenge of measure the demand for haemotherapic's products and establish parameters to control their stocks. Thus, it was sought to adapt a recent study realized out of the country, about sizing of stocks of a inventory for blood banks, combined with a forecast model of demand for blood derivatives subclassified by blood type. This control aims to increase the availability of the transfusion service, as it intends to reduce shortages and wastage of the blood collected.
\end{abstract}

Keywords: Blood Center. Demand Forecasting. Stocks management. Blood products. 


\section{INTRODUÇÃO}

Aumentar a oferta e disponibilidade de sangue coletado nos hemocentros é uma preocupação constante das instituições de saúde no Brasil e no mundo. O serviço de coleta e distribuição de sangue é primordial para manutenção de diversos serviços de assistência à vida de pacientes portadores de doenças diversas e para casos cirúrgicos. Desse modo, assegurar que esse produto esteja disponível para uso em tempo hábil, é fundamental para assegurar a prestação do serviço.

Em geral, os hemocentros são responsáveis por coletar, processar, armazenar e distribuir o sangue e seus derivados. Como o fornecimento de sangue do doador e a procura por esses produtos ocorrem de maneira aleatória, realizar a adequação entre oferta e demanda não é uma tarefa simples.

Greinacher et al. (2007) mostram que a situação dos bancos de sangue mundiais tendem a ficar críticas devido à crescente demanda por transfusões de sangue para pessoas idosas e o número reduzido de potenciais doadores de sangue. Vale ser ressaltado que existem eventos aleatórios que influenciam na demanda pelos componentes oriundos do sangue, como é o caso dos desastres naturais. Schimidt (2002) mostrou o impacto destes desastres na demanda por sangue e observa que os estoques de sangue nos EUA são estimados também em função desta variável.

No Brasil, o percentual de doadores de sangue é de cerca de $2 \%$ da população. Segundo a Organização Mundial de Saúde (OMS), esse percentual está bem abaixo do necessário, que é de $3 \%$ a $5 \%$ da população de um país. O Brasil necessita diariamente de 5.500 bolsas de sangue e, para suprir essa demanda, precisa de um número muito maior de doadores (BUSS, 2005).

De acordo com dados do Caderno de Informação Sangue e Hemoderivados (MINISTÉRIO DA SAÚDE, 2011), a taxa de doação de sangue no Brasil em 2010 teve um valor médio de $1,9 \%$ da população do país, com os menores índices obtidos nas regiões norte e nordeste, chegando a $1,4 \%$ da população.

No Estado do Rio Grande do Norte, a evolução da taxa de doação de sangue podem ser visualizadas na Tabela 1:

Revista Produção Online, Florianópolis, SC, v.14, n. 1, p. 264-293, jan./mar. 2014. 
Tabela 1 - Taxa de Doação de Sangue, Rio Grande do Norte, 2008 a 2010.

\begin{tabular}{|c|c|c|c|}
\hline \multirow{2}{*}{ População Considerada } & \multicolumn{3}{|c|}{ Taxa de Doação de Sangue } \\
\cline { 2 - 4 } & 2008 & 2009 & 2010 \\
\hline Total & $\mathbf{1 , 2 7} \%$ & $\mathbf{1 , 3 5 \%}$ & $\mathbf{1 , 4 2 \%}$ \\
\hline
\end{tabular}

Fonte: Ministério da Saúde, 2011.

Apesar da tendência no aumento na taxa de doação, é perceptível que a média estadual de doação de sangue está abaixo da recomendada pela OMS. Um fator agravante desta situação é o alto índice de descarte de bolsas de sangue, seja devido a falhas durante a coleta e processamento, prazo de validade vencido ou rejeição após os testes de controle de qualidade. Essa baixa taxa de oferta e o alto índice de descarte de bolsas de sangue se refletem na baixa disponibilidade de sangue, o que representa um risco para a vida dos pacientes.

Diante desta perspectiva, estes dados reforçam a necessidade de uma gestão adequada do estoque dos produtos derivados do sangue. A falta de controle nos inventários dos bancos de sangue pode causar diversos prejuízos, como a escassez de sangue e o desperdício. Nesse sentido, viabilizar estudos na área de controle e melhoramento do processo é de grande importância. Assim, este estudo tem como desafio dimensionar a demanda por produtos hemoterápicos e estabelecer parâmetros de controle de estoque de um banco de sangue, de forma a aumentar a disponibilidade desses produtos sem gerar desperdício.

\section{REFERENCIAL TEÓRICO}

Dentro do referencial teórico desenvolvido, quatro temas principais serão abordados. Na seção 2.1, serão apresentados os aspectos gerais do sangue, como a sua classificação quanto à tipologia. Em seguida, na seção 2.2, será apresentada a contextualização de como se dá o gerenciamento de estoques e a previsão de demanda de sangue nos hemocentros brasileiros. Na terceira parte do referencial (seção 2.3), serão abordados os conceitos e o método utilizado para fazer a previsão de demanda. Por último, o modelo de gerenciamento de estoques adotado é apresentado (seção 2.4). 


\subsection{Aspectos gerais do sangue e seus derivados}

A função do sangue é transportar substâncias de uma parte do corpo para outra, além de ser responsável por boa parte da proteção necessária para resistir aos agentes invasores (THIBODEAU e PATTON, 2002; BALOGH e FEHRENBACH, 2008).

Os tipos sanguíneos são identificados por antígenos próprios, localizados na membrana plasmática dos glóbulos vermelhos. Um antígeno é uma substância que pode ativar o sistema imunológico para dar respostas, relacionadas com a produção de anticorpos. Um anticorpo é definido como uma substância sintetizada pelo corpo em resposta ao estímulo promovido por um antígeno (THIBODEAU e PATTON, 2002). De acordo com o tipo sanguíneo do individuo, o corpo não forma anticorpo para reagir com aquele antígeno e sim com os demais.

Existem dois sistemas para classificar os tipos sanguíneos, o sistema ABO e o sistema Rh.

Conforme Jord (2004), o sistema ABO consiste na classificação por meio de dois antígenos principais, chamados $A$ e $B$. Os indivíduos podem ter um dos quatro tipos sanguíneos: tipo $A$, tipo $B$, tipo $A B$ e tipo $O$. O sistema Rh é definido em função dos antígenos que estão presentes na superfície dos eritrócitos (JORD, 2004).

O processamento do sangue pode resultar em diferentes hemocomponentes e hemoderivados, dois tipos de produtos distintos. Segundo informações do Guia para o uso de hemocomponentes (MINISTÉRIO DA SAÚDE, 2009), os produtos originados nos serviços de hemoterapia, obtidos por meio do sangue total, através de processos físicos, como a centrifugação e o congelamento, são chamados hemocomponentes. Os produtos gerados em escala industrial, obtidos por meio do fracionamento do plasma por métodos físico-químicos, são chamados de hemoderivados. O resultado do processamento por fracionamento resulta na produção dos diferentes hemocomponentes (GOMES e GONÇALEZ, 2009):

- Concentrado de hemácias $(\mathrm{CH})$;

- Concentrado de plaquetas (CP);

- Plasma fresco congelado (PFC);

- Crioprecipitado (CRIO);

Revista Produção Online, Florianópolis, SC, v.14, n. 1, p. 264-293, jan./mar. 2014. 
- Concentrado de granulócitos (CG).

O sangue coletado e não processado é conhecido como sangue total e tem sua aplicação transfusional praticamente abolida . A terapia transfusional moderna orienta fundamentalmente o uso dos componentes sanguíneos específicos indicados para tratar determinada condição clínica do paciente (GOMES e GONÇALEZ, 2009; LOPES, A. C., 2006).

\subsection{Gerenciamento de estoques e previsão de demanda em hemocentros no Brasil}

É comum ser noticiado pela mídia a carência de estoques de sangue por todo - Brasil, causando adiamento ou até mesmo cancelamento de cirurgias urgentes. Diante dessas constatações, são realizadas intensas campanhas para a captação de doadores para a reposição dos estoques e definidas metas para as coletas diárias baseadas nas experiências passadas ou, até mesmo, de acordo com as últimas requisições requisições médicas.

\footnotetext{
A gestão de sangue é um problema de interesse específico para a raça humana. Mesmo que haja desenvolvimentos tecnológicos no campo dos substitutos para os produtos de sangue, a necessidade por doadores de sangue e seus derivados sempre existirá. (BELIEN; FORCÉ, 2011).
}

Contudo, não foi observado na literatura pesquisada uma forma de cálculo para dimensionar as metas de coleta. Destaca-se ainda que o gerenciamento do estoque deste tipo de produto deve ser feito com muita atenção, dado que o sangue tem um prazo de validade entre 21 e 35 dias, a depender da forma como foi coletado, conforme definido na Portaria 1.353 do Ministério da Saúde (Ministério da Saúde, 2013).

$\mathrm{Na}$ busca por estudos na área de gerenciamento e previsão de demanda de sangue no Brasil, foi encontrado um método utilizado para este procedimento no "Guia Nacional de Gerenciamento de Estoque de Sangue em Situações de Emergência" (MINSITÉRIO DA SAÚDE, 2011). Neste documento, são indicadas medidas que devem ser feitas pela Hemorrede nacional, relacionadas aos estoques de hemocomponentes em situações adversas. Neste guia, são sugeridas medidas 
relacionadas, principalmente, à infraestrutura e à reunião de profissionais e material necessário para enfrentar a demanda por sangue em situações como desastres naturais, guerras, epidemias e em eventos especiais de grande porte. É proposto também uma série de indicadores a fim de gerenciar o andamento da operação nesses casos especiais. Nesta publicação, é definido um método para o dimensionamento do estoque mínimo (equação 1). Essa mensuração é feita a partir da demanda dos últimos seis meses de cada produto.

$\mathrm{EM}=\frac{\mathrm{NB}}{180} \times 3$

Onde,

$\mathrm{EM}=$ Estoque mínimo;

$\mathrm{NB}=$ Número de bolsas fornecidas em seis meses.

Como este estudo é restrito a situações atípicas, este método não é viável para a definição do estoque em situações normais, pois é importante uma análise aprofundada dos dados de demanda para que inferências possam ser agregadas à previsão e ao dimensionamento dos estoques, criando um modelo que represente de forma mais aproximada da realidade.

Diante do exposto, é perceptível como são limitados os estudos na área de gerenciamento dos estoques de sangue nos hemocentros do Brasil.

\subsection{Previsão de demanda}

Moreira (2011) define previsão de demanda como um processo racional de busca por informações sobre o valor das vendas futuras de um item ou um conjunto de itens, tendo em vista que é necessário ter uma estimativa da quantidade de produtos que serão vendidos, ponto de partida para praticamente todas as decisões estratégicas, táticas e operacionais de uma empresa. Werner e Ribeiro (2006), porém, entendem que os modelos estatísticos devem ser utilizados em conjunto com informações subjetivas. Neste sentido, uma análise crítica da previsão pode ser uma solução.

Lopes (2006) entende que "o método de previsão deve oferecer um modelo preditivo que represente o mais próximo possível a situação em estudo". O mesmo 
autor define ainda que se deve optar por um método sistemático, com etapas detalhadas que possam ser descritas e replicadas.

No caso do sistema transfusional de sangue, a previsão de demanda de produtos hemoterápicos tem potencial para subsidiar as decisões referentes à captação de recursos junto ao poder público, programação das atividades e captação de doadores para o alcance das metas de coleta, tornando a coordenação dos estoques um processo mais preciso.

Existem as seguintes características para a escolha de um modelo de previsão: (i) horizonte de previsão com boa acurácia; (ii) rapidez na geração das previsões, tempo de desenvolvimento e execução; (iii) facilidade para atualização das previsões; (iv) recursos matemáticos e computacionais necessários; (v) custos de implantação e manutenção do método; (vi) necessidade de dados históricos; (vii) facilidade para trabalhar com a variabilidade das séries temporais; (viii) habilidade para incorporar mudanças nas decisões gerenciais, nos fatores contextuais e nas relações entre variáveis; (ix) capacidade para obter previsões para os componentes das séries temporais; $(x)$ grau de acurácia e (xi) capacidade de identificar e incorporar mudanças de direção da demanda (LOPES, 2006).

Salgado Filho et al. (2010) definem que existem várias técnicas e modelos, dentre eles os que analisam minuciosamente dados passados para prever comportamentos futuros.

Para Carmo et al. (2009), dentre dos modelos quantitativos, a escolha do modelo de previsão é realizada em função dos dados coletados, sendo utilizados modelos baseados em séries temporais quando se obtém uma série histórica da produção do produto em estudo e modelos baseados em correlação, quando não possui um histórico de dados. Pellegrini (2000) entende que estes modelos partem do princípio de que uma série temporal pode ser representada por seus componentes separadamente, como a média, a sazonalidade e a tendência. Além destes fatores, Fogliatto et al. (2005) entendem que existe ainda o ciclo, movimento ondulatório periódico ao lado do tempo.

Os modelos baseados em séries temporais se enquadram no caso estudado nesta pesquisa, dada a representação dos componentes tendência e sazonalidade na séria histórica em estudo.

Revista Produção Online, Florianópolis, SC, v.14, n. 1, p. 264-293, jan./mar. 2014. 
Tubino (2007) define que os modelos que partem destes componentes podem ser subdivididos em etapas, estando relacionadas ao dimensionamento de cada um desses fatores. Existem, portanto, técnicas para tratar a média, a tendência e a sazonalidade.

Para incorporar essas características no modelo de previsão, é necessário seguir os passos ilustrados na figura 1.

Figura 1 - Processo de previsão de demanda com tendência e sazonalidade.

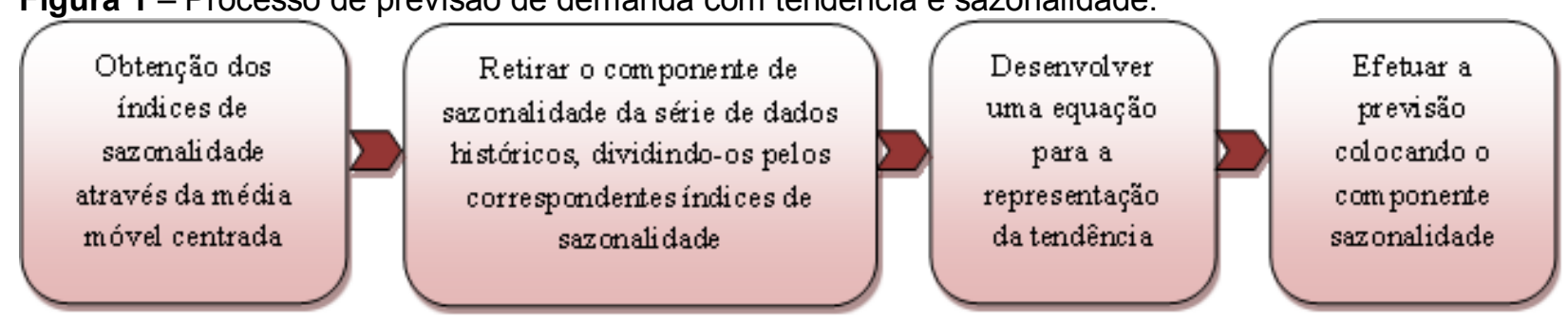

Fonte: CARMO et al. (2009), adaptado de Tubino (2007).

Para a obtenção dos índices de sazonalidade, são calculadas as médias móveis centradas para os ciclos definidos, onde o ciclo corresponde um comportamento parecido dos dados. Em seguida, as médias de cada período são divididas pelos dados históricos correspondentes de cada período, obtendo-se, assim, os índices de sazonalidade por período (CARMO et al., 2009). Retirando-se o índice de sazonalidade dos períodos, obtêm-se os valores por meio de uma curva que representa uma tendência expressa no gráfico. Assim, é possível determinar se há crescimento ou decrescimento da demanda ao longo do tempo. A partir deste novo conjunto de dados, é possível definir uma equação que represente esta demanda dessazonalizada. Por último, com a equação definida, é possível fazer previsões futuras por meio desta equação. Para a obtenção da previsão, contudo, é necessário reintegrar o componente sazonalidade.

\subsection{Gestão de estoques}

No processo de gerenciamento de estoques, são requeridas informações acerca das demandas esperadas, quantidades de estoques pedidos e disponíveis para cada produto, da mesma forma que o momento adequado para novos pedidos. (KRAJEWSKI et al., 2009)

Revista Produção Online, Florianópolis, SC, v.14, n. 1, p. 264-293, jan./mar. 2014. 
Slack et al. (2009) definem estoque como sendo a acumulação armazenada de bens materiais em um sistema de transformação. Lustosa et al. (2008) citam algumas das diversas funções dos estoques: garantir pronto atendimento; obter ganho de escala; e antecipação, de modo a atender a demanda prevista.

No caso de um banco de sangue, a função de se manter uma política de estoque está relacionado ao pronto-atendimento da demanda, sendo o produto insubstituível usado para tratar, principalmente casos de emergência. Como a missão de um hemocentro está associada à garantia do fornecimento de produtos derivados do sangue em suficiência e qualidade para a população, fatores como o ganho de escala não estão enquadrados nesse ideal, pois esse tipo de organização não objetiva o lucro.

Martins \& Laugeni (2005) sugerem uma sequencia de passos para o dimensionamento de estoques, apresentados a seguir:

- Elaborar a classificação ABC;

- Calcular os parâmetros do sistema;

- Estimar os estoques de segurança e os lotes de reposição.

Seguindo estas etapas, Leoprabhu et al. (2010) utilizaram o Diagrama de Pareto para entender o comportamento da demanda por tipo sanguíneo. Em seguida, os autores calcularam os níveis de estoque mínimo e máximo. Para a realização deste procedimento, são necessários dados de lead time de processamento do sangue, demanda máxima da série de dados histórica, média, desvio padrão e nível de satisfação exigido.

No modelo proposto por Leoprabhu et al. (2010) foram identificados quatro métodos para calcular os níveis de estoque, variando basicamente os níveis de serviço requeridos por tipo sanguíneo e o modo de relacionar a equação do estoque de segurança com o lead time demandado.

A partir dos métodos apresentados, é possível observar que a diferença entre os resultados entre eles é pequena. O método escolhido é composto por quatro equações referentes ao cálculo do estoque de segurança, lead time demandado, estoque mínimo e estoque máximo. A configuração dessas equações é sugerida também por Wild (2002). 
Para efetuar o cálculo do estoque de segurança, é necessário definir o nível de serviço (NS) requerido. Neste caso, foi proposto o NS de 99,99\% para todos os tipos sanguíneos. Esse nível de serviço é indicado devido à importância de se dispor deste produto para diversos tratamentos de saúde, nos quais há grave risco de vida. Com estes dados, é possível calcular o estoque de segurança, conforme a equação 2:

Eseg $=\mathrm{NS} \times \mathrm{LT} \times \mathrm{DP}(2)$

Onde,

Eseg = estoque de segurança;

NS = nível de satisfação do cliente;

$\mathrm{LT}$ = fator de lead time demandado;

$\mathrm{DP}=$ desvio padrão.

O Fator de Lead Time Demandado (FLT) é calculado a partir da equação 3, sendo necessário definir o Lead Time demandando (LT) e o Período Padrão (PP).

$\mathrm{FLT}=\sqrt{\frac{\mathrm{LT}}{\mathrm{pp}}}$

O lead time de processamento é auferido por meio da cronometragem de todo o processo de obtenção do sangue para, em seguida, ser calculado o Lead Time Demandado, conforme equação 4.

LTdemandado $=$ Máx LT $\times$ Máx Demanda (4)

Onde,

LT demandado = lead time demandado

Máx LT = máximo lead time de processamento;

Máx Demanda = máximo valor de demanda encontrada na série histórica dos dados.

Com essas informações, é possível calcular os níveis Mínimo e Máximo de estoque, conforme equações 5 e 6 :

Mínimo $/$ Mês = Eseg + LTdemandado (5)

Onde,

Mínimo/Mês = nível mínimo de estoque a ser mantido por mês;

Eseg = estoque de segurança;

LT demandado = lead time demandado.

Revista Produção Online, Florianópolis, SC, v.14, n. 1, p. 264-293, jan./mar. 2014. 
$\frac{\text { Máximo }}{\text { Mês }}=$ Demanda média + Mínimo/Mês

Onde,

Mínimo/Mês = nível mínimo de estoque a ser mantido por mês;

Ressalta-se que esse tipo de inventário proposto é composto por dois submodelos, dos quais um é dito inventário atribuído, quando as doações de sangue são direcionadas a um receptor específico e ao inventário não atribuído, aquele inventário recorrido em emergência por receptores desconhecidos. Leoprabhu et al. (2010) citam a situação de que em qualquer caso de emergência o produto é liberado, mesmo sendo inventário atribuído, com a perspectiva de reposição.

\section{METODOLOGIA}

Silva e Menezes (2005) definem que a pesquisa aplicada tem por finalidade gerar conhecimentos para a aplicação prática e direcionados à solução de problemas específicos. Neste sentido, a natureza desta pesquisa é aplicada, devido ao seu interesse prático, tendo em vista que será realizada a coleta e tratamento dos dados para a proposição de melhorias para o sistema de doação e processamento de sangue de um hemocentro regional.

Com relação ao método de pesquisa, ela se insere no contexto de um estudo de caso, pois envolve o estudo aprofundado de um caso de modo a permitir seu detalhamento e peculiaridades. Conforme sugerido por SEVERINO (2007), o caso a ser selecionado para a pesquisa deve ser significativo e representativo, sendo susceptível a fundamentar uma generalização para situações análogas, autorizando inferências.

As etapas para concretização deste estudo serão descritas na figura 2. 
Figura 2 - Etapas da pesquisa.

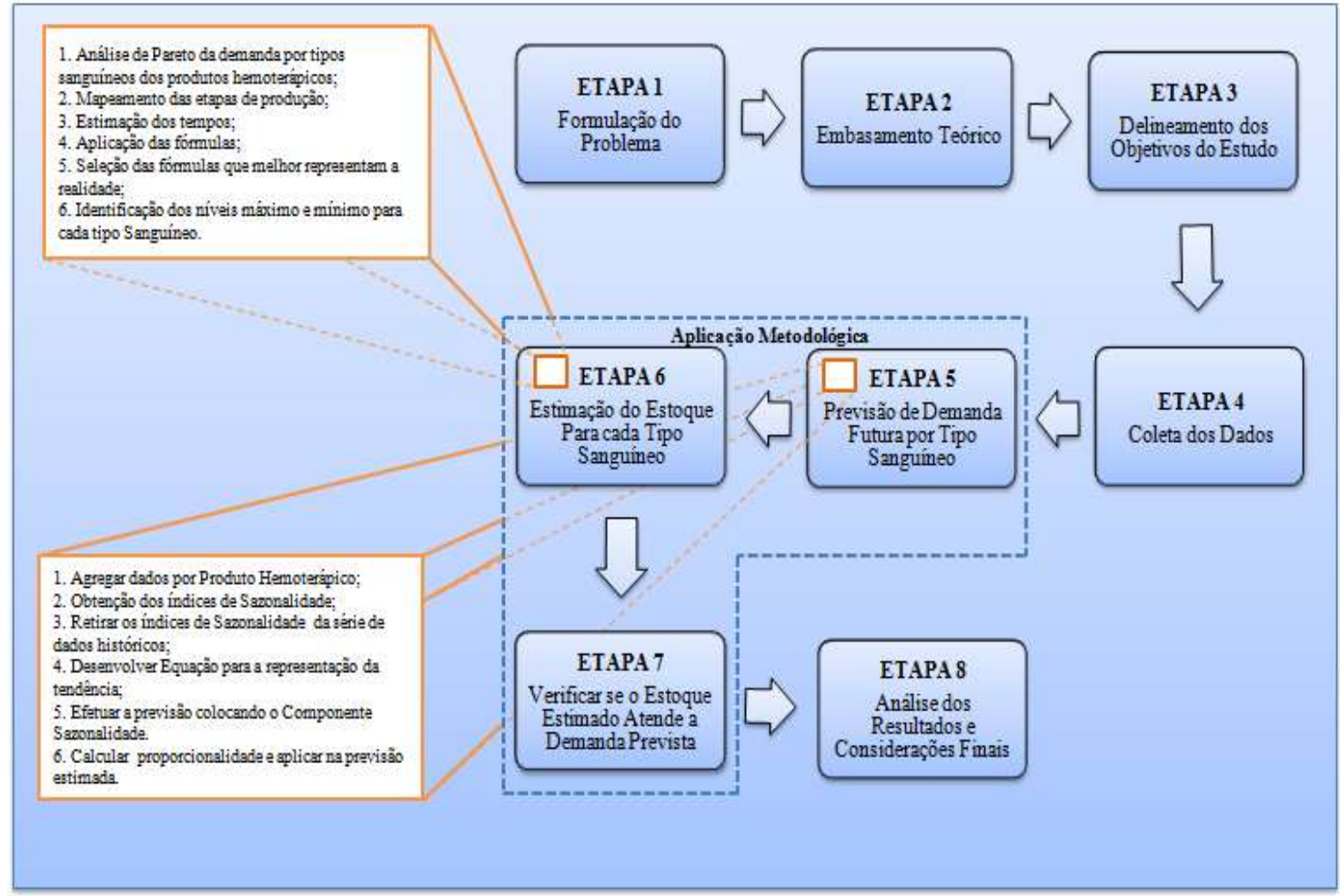

Fonte: Autores (2013).

A Etapa 1 compreende a formulação e entendimento do problema a ser estudado, tendo em vista a lacuna observada na literatura, principalmente no Brasil, com relação à falta de estudos na área de de gerenciamento e dimensionamento dos estoques para bancos de sangue.

A Etapa 2 é realizada em função do entendimento do panorama geral dos aspectos relacionados a doação de sangue e a forma de gerenciamento do material coletado. Uma revisão de literatura é realizada com o objetivo de encontrar técnicas e ferramentas para resolução do problema estudado.

A Etapa 3 representa o delineamento da pesquisa, no qual serão definidos os objetivos pretendidos e as ferramentas utilizadas no desenvolvimento da pesquisa.

A Etapa 4 está relacionada à coleta dos dados, que foi realizada por meio da aplicação de questionário para o entendimento das principais premissas inerentes ao processo de doação de sangue, bem como de seu processamento e armazenamento. Com relação aos dados documentais, foram coletados dados de registro de saída de sangue, fundamentais na identificação da demanda por tipo sanguíneo, bem como dos registros do sistema HEMOVIDA para a obtenção de informações como oferta e distribuição dos produtos sanguíneos. A cronometragem

Revista Produção Online, Florianópolis, SC, v.14, n. 1, p. 264-293, jan./mar. 2014. 
do processo é um procedimento necessário para a efetuação de cálculos para a aplicação do modelo de gestão de estoques por tipo sanguíneo.

Dentro da aplicação metodológica, são propostas duas etapas independentes (Etapas 5 e 6), na qual a ordem de precedência não implicará em prejuízos para a finalidade objetivada na etapa posterior, contudo a realização da Etapa 7 depende da concretização delas.

Como pode ser visualizado na Figura 2, a Etapa 5 será realizada conforme o modelo de previsão abordado por Tubino (2007), apresentado no item 2.3. A utilização deste modelo será feita para cada um dos produtos hemoterápicos agrupados por cada tipo sanguíneo, tendo em vista a identificação dos componentes de sazonalidade e tendência. A próxima etapa da aplicação metodológica é denominada estimação do estoque Máximo e Mínimo para cada um dos produtos hemoterápicos. Esse modelo foi derivado de um estudo intitulado "Inventory Management for Blood Banks", dos autores Leoprabhu et al. (2010), apresentado no item 2.4.

A Etapa 7 busca confrontar os resultados das Etapas 5 e 6 para a verificação da adequação dos níveis de estoques à previsão realizada. Por último, a Etapa 8 apresenta os resultados e conclusões oriundas desta pesquisa.

\section{ESTUDO DE CASO}

A seção 4 está organizada em três fases. A primeira fase apresenta a caracterização do objeto de estudo desta pesquisa. Em seguida, será apresentado o desenvolvimento do estudo. Por fim, a análise dos resultados é apresentada.

\subsection{Caracterização}

Com a finalidade de implementar uma política de disponibilidade de sangue, em setembro de 1989 foi instituído o hemocentro regional localizado no oeste potiguar. Em média, esse órgão fornece produtos hemoterápicos para onze instituições hospitalares da cidade e cinco hospitais de cidades próximas. 
A coleta de sangue é realizada de segunda a sábado. No setor onde são realizados os testes de compatibilidade do sangue do doador e receptor, observavase o funcionamento ininterrupto, visto que esses produtos podem ser solicitados a qualquer momento.

O hemocentro estudado estima que a média mensal de doações necessárias para manter o estoque de sangue é de novecentas bolsas de sangue total. Para os meses de pico como julho, esse índice sobe para 1000 (mil) bolsas. Neste caso, é possível produzir, no máximo, até três bolsas de produtos hemoterápicos diferentes para cada bolsa de sangue total.

Conforme dados coletados, foram produzidos 15.804 produtos hemoterápicos em 2011 e descartadas 7.730 bolsas desses produtos. Os principais motivos para o descarte dos produtos hemoterápicos são: as falhas durante a coleta e processamento do sangue total, o prazo de validade vencido e a rejeição após os testes de controle de qualidade (testes de AIDS, sífilis, hepatite $B$, hepatite $C$ e doença de chagas).

Em alguns casos, uma parcela da bolsa de sangue total é descartada, pois o resultado desse fracionamento deve ser aproveitado em escala industrial para a produção dos hemoderivados. Esse processamento é feito na França. Contudo, o hemocentro não atingiu os critérios exigidos para enviar esse material e, assim acaba descartando parte do material coletado.

Pela baixa taxa de doação e o alto índice de descarte de produtos hemoterápicos, representando aproximadamente $48,91 \%$ de perda por ano, a gestão dos estoques de produtos hemoterápicos para atender a demanda se tornou um desafio.

No hemocentro estudado são produzidos seis tipos de produtos hemoterápicos: plasma fresco, concentrado de hemácias, concentrado de hemácias pediátricos, concentrado de hemácias pobre em leucócitos, concentrado de plaquetas, concentrado de plaquetas coletadas por meio do procedimento aférese. O hemocomponente Crioprecipitado não é produzido, sendo requerido ao hemocentro da capital para compor o estoque, caso esse produto seja solicitado pelos pacientes.

Revista Produção Online, Florianópolis, SC, v.14, n. 1, p. 264-293, jan./mar. 2014. 


\subsection{Desenvolvimento do estudo}

A coleta dos dados referente à demanda dos anos de 2010 e 2011 foi realizada por meio do Livro de Saída de Sangue, no qual contém informações do tipo sanguíneo do receptor e produto hemoterápico requisitado. Os dados de 2012 não foram coletados, pois o livro de saída de sangue estava sendo utilizado. Por este motivo, foram utilizados somente os dados de 2010 e 2011.

Os dados foram segregados por mês, totalizando as quantidades do produto hemoterápico por tipo sanguíneo nos respectivos períodos. As bolsas que armazenam os produtos hemoterápicos podem conter volumes variados, a partir do volume de sangue coletado na doação e quantidade demandada na requisição médica.

A tabela 2 ilustra a série histórica coletada, segmentada por tipo de produto hemoterápico e tipo sanguíneo (no caso da tabela 2, está ilustrado o plasma fresco). Da mesma forma foram realizadas as coletas dos outros produtos hemoterápicos.

Tabela 2 - Demanda Real por Plasma Fresco em 2010 e 2011

\begin{tabular}{|c|c|c|c|c|c|c|c|c|}
\hline & \multicolumn{8}{|c|}{$\begin{array}{c}\text { Demanda Real por Bolsas de Plasma Fresco } \\
\text { Tipo Sanguíneo }\end{array}$} \\
\hline Período & A+ & B+ & AB+ & O+ & A- & B- & AB- & O- \\
\hline Jan/10 & 24 & 32 & 1 & 19 & 0 & 1 & 6 & 5 \\
\hline Fev/10 & 54 & 7 & 3 & 35 & 0 & 0 & 0 & 2 \\
\hline Mar/10 & 42 & 26 & 2 & 23 & 0 & 4 & 0 & 2 \\
\hline Abr/10 & 13 & 0 & 0 & 34 & 1 & 0 & 0 & 1 \\
\hline Mai/10 & 39 & 8 & 5 & 51 & 0 & 0 & 0 & 2 \\
\hline Jun/10 & 20 & 8 & 0 & 36 & 0 & 0 & 0 & 1 \\
\hline Jul/10 & 15 & 7 & 0 & 15 & 0 & 1 & 0 & 2 \\
\hline Ago/10 & 6 & 3 & 0 & 5 & 0 & 0 & 0 & 4 \\
\hline Set/10 & 13 & 0 & 0 & 40 & 0 & 0 & 0 & 8 \\
\hline Out/10 & 10 & 15 & 0 & 33 & 0 & 0 & 0 & 5 \\
\hline Nov/10 & 15 & 7 & 5 & 45 & 7 & 0 & 0 & 23 \\
\hline Dez/10 & 19 & 0 & 10 & 152 & 1 & 0 & 0 & 3 \\
\hline Jan/11 & 17 & 4 & 3 & 23 & 0 & 0 & 0 & 0 \\
\hline Fev/11 & 38 & 0 & 0 & 20 & 3 & 0 & 0 & 3 \\
\hline Mar/11 & 57 & 7 & 0 & 22 & 2 & 0 & 0 & 18 \\
\hline $\mathrm{Abr} / 11$ & 28 & 6 & 2 & 18 & 0 & 0 & 0 & 7 \\
\hline Mai/11 & 24 & 1 & 0 & 60 & 2 & 0 & 0 & 7 \\
\hline Jun/11 & 15 & 6 & 0 & 17 & 0 & 0 & 0 & 16 \\
\hline Jul/11 & 34 & 13 & 0 & 39 & 0 & 4 & 0 & 0 \\
\hline Ago/11 & 21 & 0 & 0 & 31 & 1 & 0 & 5 & 5 \\
\hline Set/11 & 120 & 6 & 0 & 9 & 0 & 0 & 0 & 2 \\
\hline Out/11 & 64 & 10 & 0 & 41 & 6 & 0 & 0 & 11 \\
\hline Nov/11 & 14 & 36 & 0 & 25 & 5 & 0 & 0 & 0 \\
\hline Dez/11 & 31 & 9 & 0 & 9 & 3 & 0 & 0 & 2 \\
\hline
\end{tabular}

Fonte: Elaborado pelos Autores (2013).

Revista Produção Online, Florianópolis, SC, v.14, n. 1, p. 264-293, jan./mar. 2014. 
Em seguida, os dados foram separados por tipo sanguíneo e agregados por tipo de produto hemoterápico. Esse procedimento foi adotado dado de que os tipos sanguíneos seguem o mesmo comportamento. A Figura 4 ilustra o comportamento dos dados referentes ao plasma fresco no período de 2010 a 2011, da mesma forma acontece com os outros produtos hemoterápicos.

Figura 4 - Demanda Real do Plasma Fresco por Tipo Sanguíneo em 2010 e 2011.

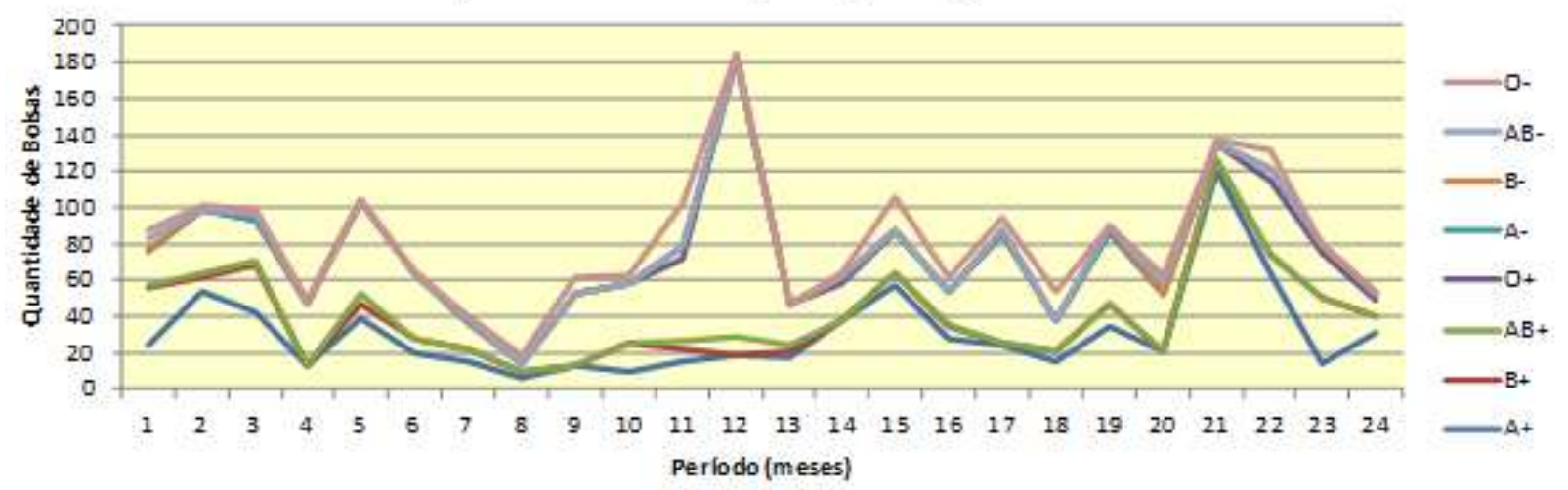

Fonte: Elaborado pelos Autores (2013).

Por meio da Figura 4, é possível constatar que existem picos de demanda nos meses relacionados de fevereiro e março (carnaval), no mês de maio e nos últimos meses do ano, quando ocorrem as festas de final de ano. Esse comportamento está relacionado ao maior número de acidentes e, desse modo, maior demanda por produtos sanguíneos por parte dos hospitais.

Agregando-se os dados do plasma fresco, observou-se a existência do componente tendência. Este aumento pode se dá em função do aumento do número de cirurgias cardíacas, sendo este tipo de procedimento um fator que demanda o serviço de hemoterapia, além de fatores como o crescimento da população, e atendimento das demandas do Centro de Oncologia. Este fato não ocorre somente no Brasil nem é um fato novo. O estudo realizado por Roche e Stengle (1973) mostrou que a frequência dos procedimentos que exigem circulação extracorpórea apresentam um ritmo de crescimento grande, resultando no aumento na demanda por sangue.

Dessa forma, foram realizados os mesmo procedimentos para os demais produtos hemoterápicos e percebeu-se que as demandas apresentam os 
componentes sazonalidade e tendência. Esses dois fatores são decisivos para a escolha do modelo de previsão de demanda.

Optou-se por seguir a metodologia de Tubino (2007) para previsão baseada em séries temporais. Corroborando com a ideia de Lopes F. O. (2006), a escolha do modelo de previsão se deu em função das seguintes características: (i) o horizonte de previsão obtido por meio deste modelo serve para o curto prazo com boa acurácia e pode servir de base para planejamentos de longo prazo; (ii) o método é de fácil aplicação e entendimento, o que facilita a utilização do mesmo por pessoas que não são expertises na área; (iii) os dados são facilmente atualizados por meio da técnica de média móvel; (iv) o modelo pode ser implantando facilmente com o recurso de planilhas eletrônicas, não exigindo um software específico para tal fim; (v) custo de implantação baixo pela não necessidade de aquisição de software; (vi e vii) existe uma série de dados históricos consistente; (viii) é passível de alteração em função de mudanças de comportamento observadas; dentre outras vantagens.

A seguir serão descritos os procedimentos realizados no tratamento dos dados referentes ao produto hemoterápico plasma fresco. Ressalta-se que os mesmos procedimentos foram realizados para os outros quatro produtos citados. Dessa forma serão mostrados apenas os resultados dos outros casos.

Definido o ciclo de sazonalidade, a média móvel centrada no meio do período (MMCP) foi calculada com base nos dados da demanda real dos anos de 2010 e 2011, totalizando vinte e quatro períodos. Em seguida, foi calculado o índice de sazonalidade. O passo seguinte consistiu em retirar o componente sazonalidade da série de dados históricos. A partir da demanda dessazonalizada, é possível obter uma equação para representar o comportamento dos dados (Equação 7).

$$
\mathrm{Y}=-2,0996 \mathrm{X}+146,47
$$

Na tabela 3 são apresentados os valores de projeção para os próximos dois anos. Na tabela 4, é possível visualizar as demandas projetadas para os anos de 2012 e 2013 de todos os produtos hemoterápicos. 


\begin{tabular}{|c|c|c|c|c|c|c|c|c|c|}
\hline \multicolumn{5}{|c|}{$\begin{array}{c}\text { Tabela } 3 \text { - Projeção da Demanda por Plasma } \\
\text { Fresco para } 2012 \text { e } 2013 .\end{array}$} & \multicolumn{5}{|c|}{$\begin{array}{c}\text { Tabela } 4 \text { - Demanda prevista dos produtos } \\
\text { hemoterápicos em } 2012 \text { e } 2013\end{array}$} \\
\hline \multicolumn{5}{|c|}{ Demanda Prevista para 2012 e 2013 - PF } & \multicolumn{5}{|c|}{ Demanda Prevista } \\
\hline & & Demanda & & & Período & PF & $\mathrm{CH}$ & CHPL & $\mathbf{C P}$ \\
\hline Mês/Ano & Período & $\begin{array}{c}\text { dessazonalizad } \\
a\end{array}$ & IS & D. P. & Jan/12 & 88 & 348 & 106 & 40 \\
\hline jan/12 & 25 & 93,98 & 0,5024 & $\begin{array}{l}\text { D. } P . \\
47\end{array}$ & Fev/12 & 101 & 321 & 182 & 43 \\
\hline fev/12 & 26 & 91,8804 & 0,2357 & $\begin{array}{l}42 \\
22\end{array}$ & Mar/12 & 99 & 368 & 148 & 37 \\
\hline mar/12 & 27 & 89,7808 & 0,812 & 73 & $\mathrm{Abr} / 12$ & 49 & 465 & 102 & 55 \\
\hline$a b r / 12$ & 28 & 87,6812 & 0,8299 & 73 & Mai/12 & 105 & 428 & 133 & 125 \\
\hline $\mathrm{mai} / 12$ & 29 & 85,5816 & 1,3428 & 115 & Jun/12 & 65 & 472 & 109 & 64 \\
\hline jun/12 & 30 & 83,482 & 2,4653 & 206 & Jul/12 & 40 & 376 & 134 & 33 \\
\hline$j u l / 12$ & 31 & 81,3824 & 0.613 & 50 & Ago/12 & 18 & 455 & 109 & 162 \\
\hline $\mathrm{ago} / 12$ & 32 & 79.2828 & 0,7938 & 63 & Set/12 & 61 & 353 & 137 & 93 \\
\hline set/12 & 33 & 77,1832 & 1,2374 & 96 & Out/12 & 63 & 311 & 162 & 93 \\
\hline out/12 & 34 & 75,0836 & 0,6652 & 50 & Nov/12 & 102 & 400 & 156 & 194 \\
\hline nov/12 & 35 & 72.984 & 1.0036 & 73 & Dez/12 & 185 & 519 & 131 & 59 \\
\hline dez/12 & 36 & 70.8844 & 0.6186 & 44 & Jan/13 & 47 & 422 & 117 & 91 \\
\hline jan $/ 13$ & 37 & 68.7848 & 0.5024 & 35 & Fev/13 & 64 & 420 & 204 & 220 \\
\hline $\mathrm{fev} / 13$ & 38 & 66,6852 & 0,2357 & 16 & Mar/13 & 106 & 614 & 160 & 348 \\
\hline $\mathrm{mar} / 13$ & 39 & 64,5856 & 0812 & 52 & $\mathrm{Abr} / 13$ & 61 & 490 & 129 & 190 \\
\hline $\mathrm{abr} / 13$ & 40 & 62,486 & 0,012 & 52 & Mai/13 & 94 & 426 & 129 & 181 \\
\hline $\mathrm{mai} / 13$ & 41 & 60,3864 & 13428 & 81 & Jun/13 & 54 & 501 & 172 & 255 \\
\hline iun/13 & 42 & 58.2868 & 24653 & 144 & $\mathrm{Jul} / 13$ & 90 & 575 & 62 & 238 \\
\hline iil//13 & 43 & $56187 ?$ & 0,613 & 34 & $\mathrm{Ago} / 13$ & 63 & 511 & 169 & 218 \\
\hline (13) & 44 & 540876 & 07938 & 43 & Set/13 & 137 & 473 & 197 & 182 \\
\hline $\operatorname{cet} / 13$ & 45 & 54,988 & 0,1930 & $\begin{array}{l}40 \\
64\end{array}$ & Out/13 & 132 & 455 & 145 & 148 \\
\hline 列 113 & 46 & 498884 & 1, 20654 & 33 & Nov/13 & 80 & 479 & 101 & 136 \\
\hline 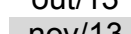 & 40 & 47,0004 & , & 48 & Dez/13 & 54 & 497 & 94 & 61 \\
\hline dez/13 & & $15689 ?$ & 06186 & 28 & & & & & \\
\hline $\mathrm{dez} / 13$ & 48 & 45,6892 & 0,0186 & 28 & & & & & \\
\hline
\end{tabular}

Fonte: Elaborado pelos Autores (2013).

A partir dos dados da tabela 4, foi realizado um cálculo de proporcionalidade com base na demanda real e na projeção futura para cada produto hemoterápico. A estratégia de se aplicar a proporcionalidade foi usada devido ao grande volume de dados tratados. Os valores das proporcionalidades para o plasma fresco podem ser observados na figura 6.

Revista Produção Online, Florianópolis, SC, v.14, n. 1, p. 264-293, jan./mar. 2014. 
Figura 6 - Proporcionalidades aplicadas nas demandas futuras do plasma fresco
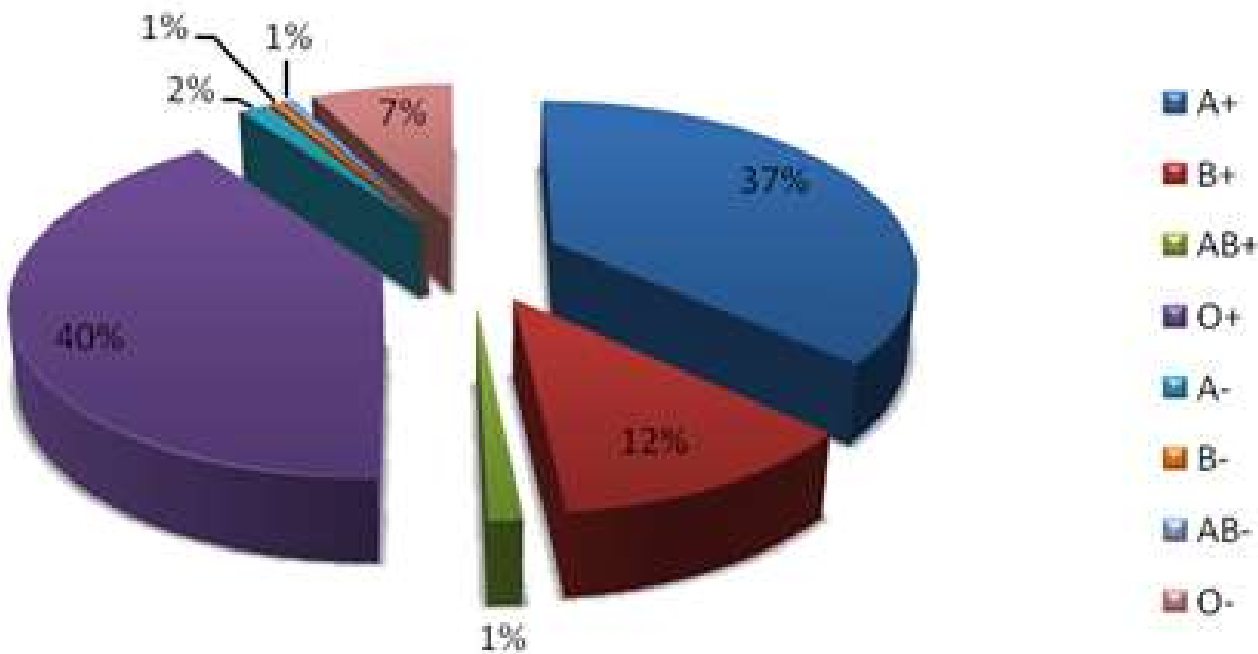

Fonte: Elaborado pelos Autores (2013).

A previsão de demanda foi usada para validar o dimensionamento do estoque, com o intuito de verificar se o valor de demanda previsto estava contido dentro do intervalo de estoque obtido pela aplicação do modelo.

Para avaliar a importância de cada item de estoque para o hemocentro, foi construído um gráfico baseado no Princípio de Pareto para observar os produtos que possuem maior demanda. Desse modo, foram agregados os valores de demanda real para cada subproduto durante os dois anos, período que representa a base de dados. A Figura 7 ilustra o diagrama construído.

Os produtos classificados como itens de classe A são: o concentrado de hemácias $\mathrm{O}+$ e o concentrado de hemácias $\mathrm{A}+$, itens que representam cerca de $40 \%$ da demanda total por produtos hemoterápicos. 
Figura 7 - Diagrama de Pareto/Curva ABC dos produtos hemoterápicos

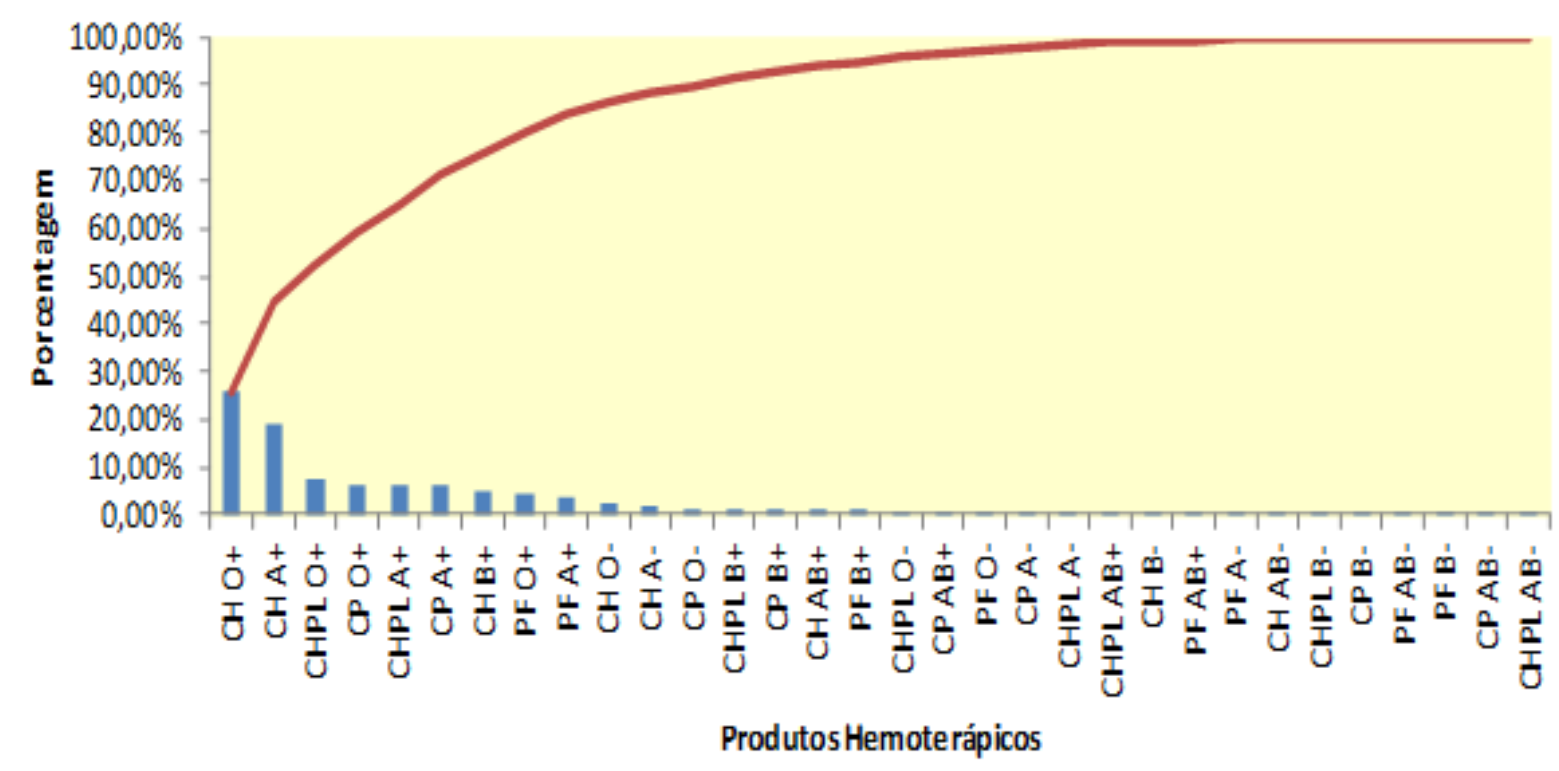

\% Demanda PorcentagemDemanda Acumulada

Fonte: Elaborado pelos Autores (2013).

A curva $A B C$ mostrou que os tipos sanguíneos mais requisitados foram o $\mathrm{O}+$ e A+ do produto hemoterápico concentrado de hemácias. Dessa forma, os gestores do hemocentro devem ficar atentos quanto à disponibilidade desses hemocomponentes, de forma a manter estoque destes itens. Dentre os produtos que possuem menor demanda estão os produtos hemoterápicos dos tipos sanguíneos Be AB-.

Essa circunstância deve-se ao fato de que na população brasileira os grupos mais comuns são o tipo $\mathrm{O}$ e tipo $\mathrm{A}$, que juntos abrangem $87 \%$ da população. $\mathrm{O}$ tipo sanguíneo $B$ corresponde a $10 \%$ e o $A B$, por apenas $3 \%$. O tipo sanguíneo também é identificado pelo fator Rh positivo ou negativo. Dentre a população brasileira, cerca de $85 \%$ das pessoas apresentam o fator Rh positivo. (BEM ESTAR, 2012)

Para realizar o cálculo dos estoques, o primeiro passo foi estimar os tempos de processamento de cada produto hemoterápico. Desse modo, foram cronometrados os tempos de cada etapa referente ao tratamento do sangue total para obter o respectivo hemocomponente. Os tempos foram coletados segundo as etapas detalhadas na figura 4. A tabela 5 apresenta os tempos de processamento para cada produto.

Revista Produção Online, Florianópolis, SC, v.14, n. 1, p. 264-293, jan./mar. 2014. 
Tabela 5 - Tempo de processamento dos produtos hemoterápicos

\begin{tabular}{lc|}
\hline \multicolumn{1}{|c|}{ Produto Hemoterápico } & Lead Time (Horas) \\
\hline 1. Plasma Fresco & 28,929 \\
2. Concentrado de Hemácias & 28,079 \\
3. Concentrado de Hemácias Pobre em & \\
Leucócitos & 30,579 \\
4. Concentrado de Plaquetas & 29,762 \\
\hline
\end{tabular}

Fonte: Elaborado pelos Autores (2013).

A partir do tempo de processamento, foi calculado o fator de lead time, necessário para compor o estoque de segurança. Para o plasma fresco, procedeuse da seguinte maneira: primeiramente foi observada a relação entre o referido lead time com o total de horas de um mês, ou seja, 720 horas considerando o mês com 30 dias, pois o PP representa a periodicidade a qual se refere o desvio padrão dos dados da demanda.

$$
\begin{aligned}
& \text { fator de Lead Time }=\sqrt{\frac{28,929}{720}} \\
& \text { fator de Lead Time }=0,2
\end{aligned}
$$

A partir dos dados da demanda real, calcula-se a média, o desvio padrão e destaca-se o maior valor encontrado da demanda entre os dados disponíveis. Essas importâncias serão necessárias para compor o cálculo do estoque. A tabela 6 ilustra o procedimento realizado para o item plasma fresco.

Tabela 6 - Parâmetros da demanda real para cálculo de estoques

\begin{tabular}{lcccccccc}
\hline \multicolumn{7}{c}{ Produto Hemoterápico - Plasma Fresco } \\
\hline & $\mathbf{A +}$ & $\mathbf{B +}$ & $\mathbf{A B +}$ & $\mathbf{O}+$ & $\mathbf{A}-$ & $\mathbf{B}-$ & $\mathbf{A B}-$ & $\mathbf{0}-$ \\
\hline Média & 30,54 & 8,79 & 1,29 & 33,42 & 1,29 & 0,42 & 0,46 & 5,38 \\
Máximo/ Mês & 120 & 36 & 10 & 152 & 7 & 4 & 6 & 23 \\
Desvio Padrão & 24,58 & 9,72 & 2,44 & 28,75 & 2,07 & 1,14 & 1,56 & 6,02 \\
\hline
\end{tabular}

Fonte: Elaborado pelos Autores (2013)

Foi adotado como nível de serviço requerido $99,99 \%$ para todos os grupos sanguíneos, ou seja, um fator de serviço de 3,620. Definidas todas as variáveis das equações relacionadas ao cálculo do estoque de segurança, do estoque máximo e do estoque mínimo (eq. 2 a 5), foram definidos os níveis de estoque para cada produto. A tabela 7 ilustra os valores encontrados para cada produto hemoterápico e seus respectivos tipos sanguíneos.

Revista Produção Online, Florianópolis, SC, v.14, n. 1, p. 264-293, jan./mar. 2014. 
Tabela 7 - Níveis de estoques para os produtos hemoterápicos.

\begin{tabular}{|c|c|c|c|}
\hline \multicolumn{4}{|c|}{ Níveis de Estoque } \\
\hline \multicolumn{4}{|c|}{ Plasma Fresco } \\
\hline Tipo Sanguíneo & Estoque de Segurança & Mín/Mês & Máx/Mês \\
\hline $\mathrm{A}+$ & 19 & 24 & 144 \\
\hline$B+$ & 8 & 9 & 45 \\
\hline$A B+$ & 2 & 3 & 13 \\
\hline $\mathrm{O}+$ & 22 & 28 & 180 \\
\hline A- & 2 & 2 & 9 \\
\hline B- & 1 & 2 & 6 \\
\hline$A B-$ & 2 & 2 & 8 \\
\hline O- & 5 & 6 & 29 \\
\hline \multicolumn{4}{|c|}{ Concentrado de Hemácias } \\
\hline Tipo Sanguíneo & Estoque de Segurança & Mín/Mês & Máx/Mês \\
\hline$A+$ & 23 & 31 & 239 \\
\hline$B+$ & 12 & 14 & 88 \\
\hline$A B+$ & 4 & 5 & 29 \\
\hline $\mathrm{O}+$ & 25 & 36 & 306 \\
\hline A- & 7 & 8 & 43 \\
\hline B- & 3 & 3 & 13 \\
\hline$A B-$ & 2 & 2 & 9 \\
\hline O- & 7 & 9 & 45 \\
\hline \multicolumn{4}{|c|}{ Concentrado de Hemácias Pobre em Leucócitos } \\
\hline Tipo Sanguíneo & Estoque de Segurança & Mín/Mês & Máx/Mês \\
\hline At & 11 & 14 & 86 \\
\hline$B+$ & 4 & 5 & 26 \\
\hline$A B+$ & 2 & 3 & 13 \\
\hline $\mathrm{O}+$ & 15 & 19 & 111 \\
\hline A- & 3 & 3 & 15 \\
\hline B- & 1 & 2 & 6 \\
\hline AB- & 1 & 1 & 4 \\
\hline O- & 3 & 3 & 17 \\
\hline \multicolumn{4}{|c|}{ Concentrado de Plaquetas } \\
\hline Tipo Sanguíneo & Estoque de Segurança & Mín/Mês & Máx/Mês \\
\hline$A+$ & 28 & 33 & 165 \\
\hline$B+$ & 18 & 22 & 124 \\
\hline$A B+$ & 8 & 10 & 49 \\
\hline $\mathrm{O}+$ & 28 & 33 & 162 \\
\hline A- & 8 & 9 & 47 \\
\hline B- & 2 & 3 & 15 \\
\hline AB- & 2 & 2 & 12 \\
\hline O- & 15 & 17 & 75 \\
\hline
\end{tabular}

Fonte: Elaborado pelos Autores (2013).

Os valores do estoque de segurança são diferentes do estoque mínimo, pois os mesmos são usados para compor o cálculo do estoque mínimo, mesmo procedimento utilizado para o cálculo do estoque máximo. Alguns autores referenciam o estoque mínimo como o estoque de segurança, contudo, segue-se a metodologia apresentada no referencial teórico. 


\subsection{Análise dos resultados}

Com o objetivo de observar possíveis incoerências nas demanda projetadas, foi elaborado um gráfico para comparar os dados da demanda real com os da demanda prevista, ilustrado na Figura 8 , relacionadas à demanda agregada dos produtos hemoterápicos. O tracejado indica o início da demanda prevista para 2012 e 2013.

A partir da Figura 8 é possível perceber que a demanda real e projetada para cada um dos produtos apresentam comportamentos coerentes para todos os produtos hemoterápicos, com exceção do produto concentrado de plaquetas (CP), onde os resultados mostraram quantidades bem acima dos números da demanda real, com picos de demanda próximos a oitocentas bolsas, tornando o modelo de previsão adotado para o concentrado de plaquetas insatisfatório.

Figura 8 - Demanda real e prevista dos produtos hemoterápicos

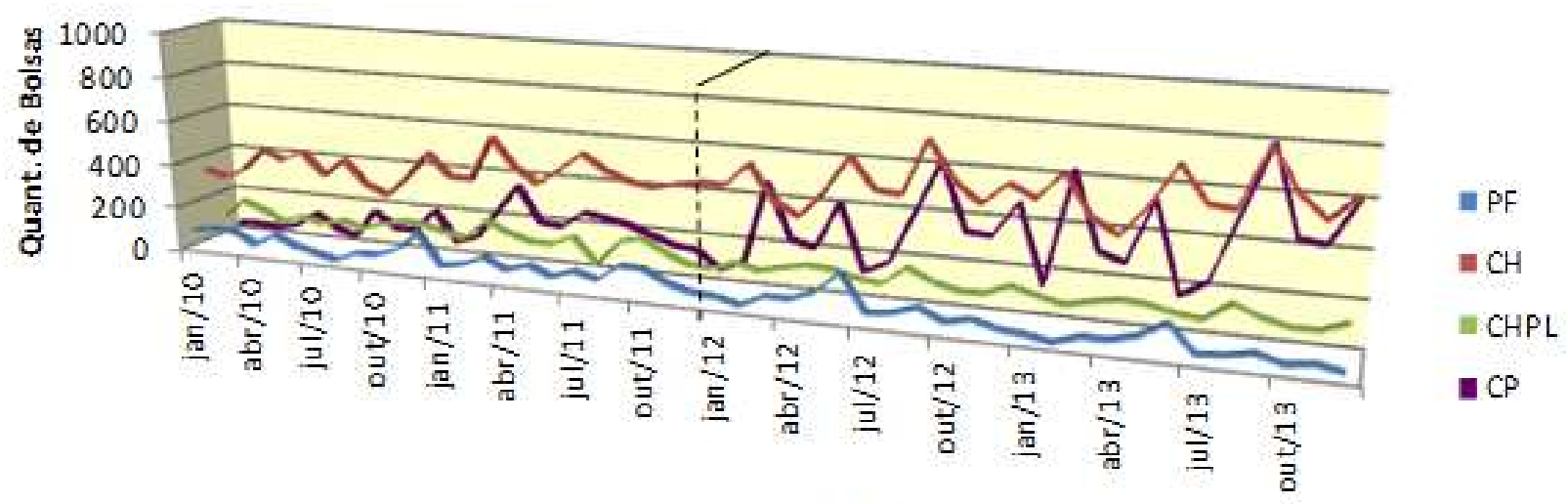

Períodos (Meses/ano)

Fonte: Elaborado pelos Autores (2013)

Com a finalidade de verificar se a demanda prevista está de acordo com os níveis de estoques calculados, foram organizados os gráficos de demanda prevista para 2012 e 2013 com os níveis de estoques estabelecidos. As figuras 10, 11 e 12 referem-se ao plasma fresco. A linha em azul representa as quantidades previstas da demanda para o produto hemoterápico específico nos períodos detalhados nas figuras. As demais linhas estão relacionadas aos valores fixos dos níveis de 
estoques máximo, mínimo e de segurança, sendo representados pelas linhas nas cores vermelho, verde e amarelo, respectivamente.

No caso do plasma fresco $\mathrm{A}+$, a demanda prevista encontra-se enquadrada dentro do nível máximo especificado para o estoque, desse modo verifica-se que exceder a cota de 144 bolsas por mês causará desperdício. Observa-se também que o estoque máximo está bem acima dos valores da demanda projetada, este fato se dá em função do nível de serviço de 99.99\%.

A quantidade especificada de estoque mínimo de 24 bolsas está entre as menores demandas previstas, ou seja, esse nível é um estado de atenção para que a equipe de planejamento da produção defina um lote de ressuprimento em curto prazo. O estoque de segurança com 19 bolsas é indicado para que não se tenham estoques zerados do produto.

Analogamente, foi realizado para todos os demais subprodutos a mesma análise. Todos os produtos possuem a demanda prevista abaixo do nível máximo de estoque. Contudo, na maior parte dos gráficos, a demanda prevista contém valores abaixo no nível de estoque mínimo e de segurança. Esse fato decorre do nível de serviço estabelecido de 99,99\%, gerando valores de níveis estoques altos para manter a disponibilidade dos produtos, vista a importância de salvar vidas.

A partir dos resultados do modelo de previsão de demanda e do cálculo dos estoques, foi possível verificar se a projeção estava adequada aos níveis de estoque calculados com base na demanda real dos produtos. Foram encontrados três tipos de padrões de comportamento que relacionavam a demanda prevista com os níveis de estoques para cada produto hemoterápico especificamente. São eles:

- Padrão 1: as quantidades demandas previstas encontram-se abaixo do nível de estoque máximo, contudo esses valores permeiam entre o nível mínimo e de segurança, como mostra a Figura 9.

Revista Produção Online, Florianópolis, SC, v.14, n. 1, p. 264-293, jan./mar. 2014. 
Figura 9 - Demanda Prevista com Níveis de Estoque para o Plasma Fresco A+

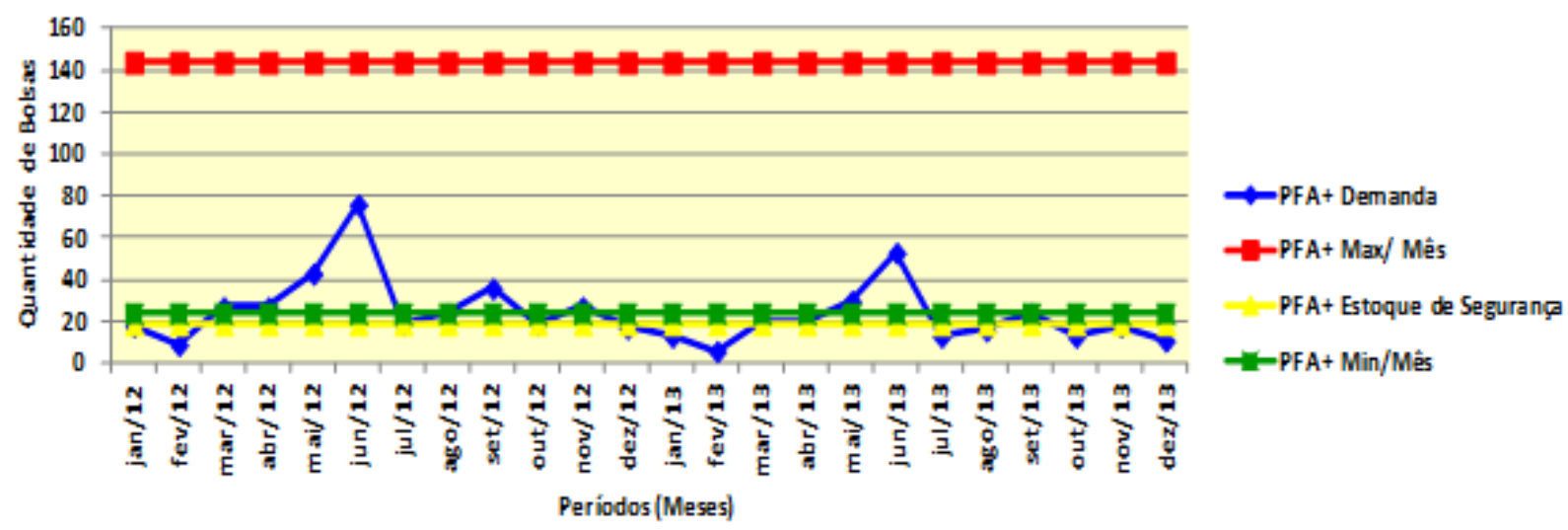

Fonte: Elaborado pelos Autores (2013).

Isso indica que é interessante se trabalhar com o nível de estoques próximo ao mínimo para evitar desperdício. Dessa forma, convém trabalhar com os estoques mínimos, por estarem mais adequados ao modelo de previsão, uma vez que trabalhar em atingir estoques máximos pode causar desperdício dos produtos hemoterápicos. Sugere-se ainda que se trabalhe com um nível de serviço menor, dado que o valor utilizado gerou uma superestimação dos estoques.

- Padrão 2: a demanda prevista está contida entre os níveis de estoque máximo, mínimo e de segurança, fato decorrente em demandas previstas maiores que dez bolsas do produto hemoterápico nos períodos, conforme mostra a Figura 10.

Figura 10 - Demanda Prevista com Níveis de Estoque para o concentrado de hemácias O-

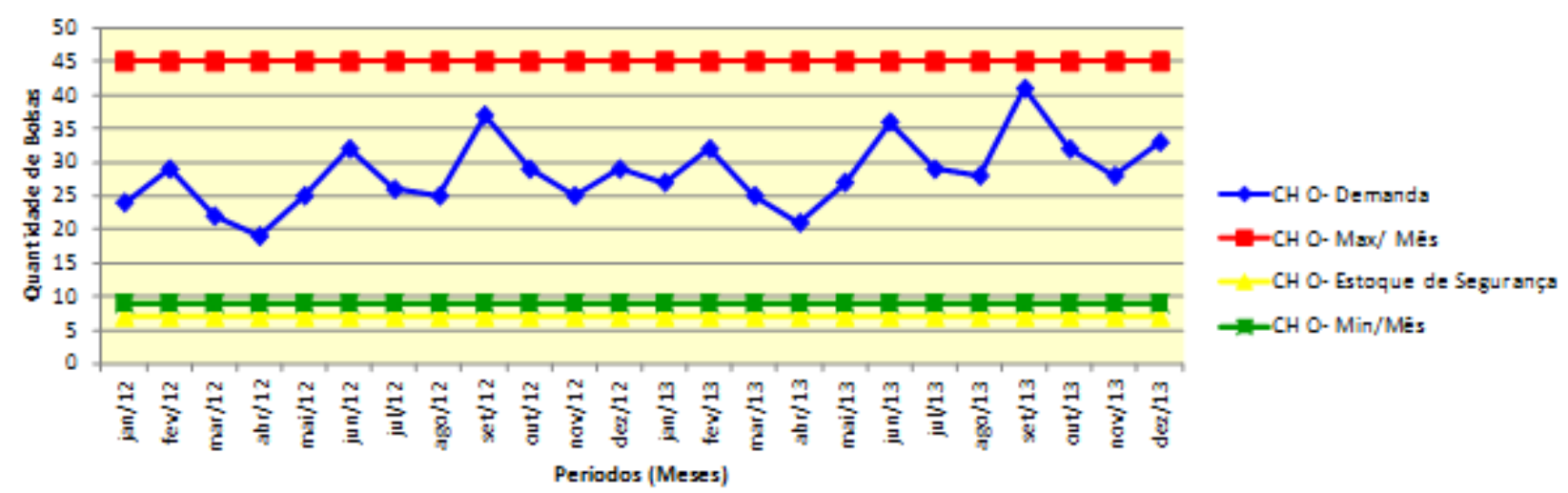

Fonte: Elaborado pelos Autores (2013).

Revista Produção Online, Florianópolis, SC, v.14, n. 1, p. 264-293, jan./mar. 2014. 
No caso dos produtos que seguem o comportamento da Figura 10, o modelo de gestão de estoques aplicado é satisfatório, estando o nível de estoque em um patamar que possibilita uma segurança no fornecimento sem gerar muito desperdício.

- Padrão 3: a demanda prevista ultrapassa o valor atribuído para o nível de estoque máximo, conforme ilustra a Figura 11.

Figura 11 - Demanda Prevista com pontos fora dos Níveis de Estoque para o concentrado de plaquetas $\mathrm{O}+$

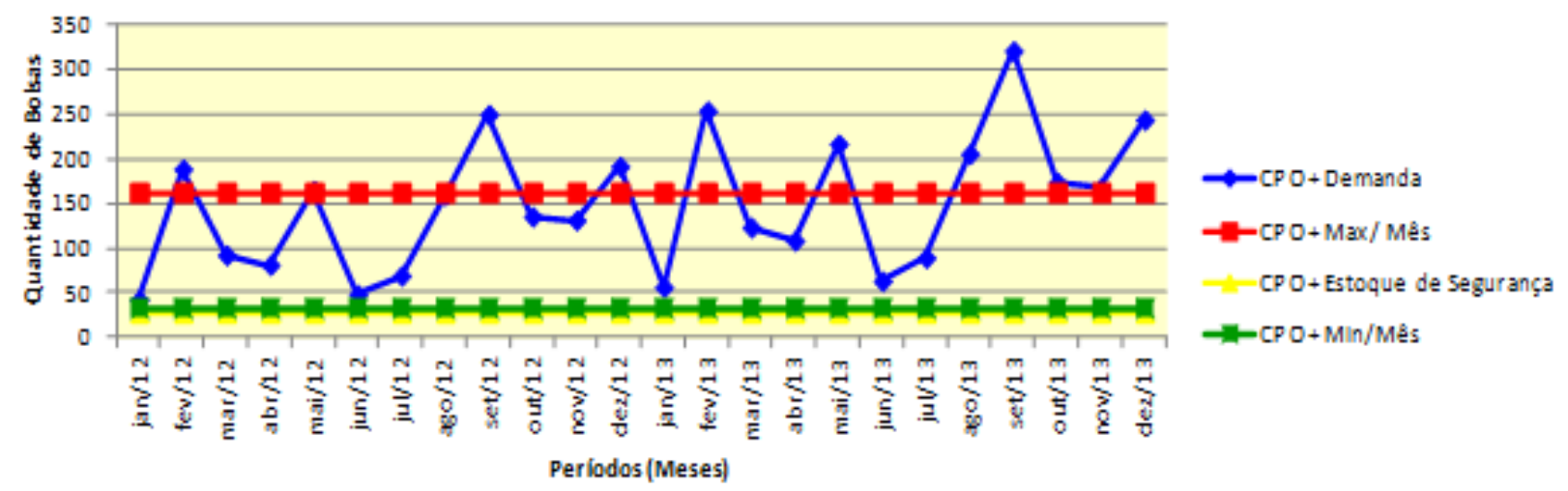

Fonte: Elaborado pelos Autores (2013).

Neste caso, observa-se que o modelo de gestão de estoques não se enquadra bem ao caso, gerando falta de produtos em vários períodos do ano. Assim, faz-se necessário adotar um maior nível de estoque, ou ainda adotar outro modelo, de forma a garantir a falta do produto.

Como a demanda prevista apresenta valores acima da demanda real, entende-se que o nível máximo estabelecido poderá não ser ultrapassado. Portanto, verificar se os níveis de estoque estão apropriados à previsão de demanda não é possível, tendo em vista as incoerências da demanda projetada.

A Tabela 8 apresenta um resumo que ilustra quais produtos hemoterápicos seguem cada um dos padrões identificados. 
Tabela 8 - Níveis de estoques para os produtos hemoterápicos.

Padrão Identificado

Padrão 1: demanda prevista próxima ao nível mínimo / estoque de segurança

Padrão 2: demanda prevista contida entre os níveis de estoque máximo

Padrão 3: demanda prevista ultrapassa o valor atribuído para o nível de estoque máximo

Fonte: Elaborado pelos Autores (2013).

\section{Produtos}

PF A+, PF B+, PF AB+, PF O+, PF A-, PF B-, PF AB-, PF O-, CH AB-, CHPL B-, CHPL AB-, $\mathrm{CP} \mathrm{B}+, \mathrm{CP} \mathrm{AB}+, \mathrm{CP} A-, \mathrm{CP} \mathrm{B}-, \mathrm{CP} \mathrm{O}-$

$\mathrm{CH}+\mathrm{B}+, \mathrm{CH} \mathrm{AB}+, \mathrm{CH}$-, $\mathrm{CH}$ B-, $\mathrm{CH}$ O-, $\mathrm{CHPL}$ $\mathrm{A}+, \mathrm{CHPL} \mathrm{B}+, \mathrm{CHPL} \mathrm{AB}+, \mathrm{CHPL} \mathrm{O}+, \mathrm{CHPL}$ $\mathrm{A}-, \mathrm{CHPL} \mathrm{O}-, \mathrm{CP} \mathrm{AB}-$

$\mathrm{CH}+, \mathrm{CHO}+, \mathrm{CP} \mathrm{A}+, \mathrm{CP} \mathrm{O}+$

Assim, constata-se que existe a necessidade de adotar diferentes modelos de previsão para cada um dos produtos identificados, em função dos resultados observados no Quadro 1.

\section{CONCLUSÕES}

Em grande parte dos estudos relacionados ao gerenciamento de bancos de sangue, a demanda é dimensionada por tipo sanguíneo. Esse tipo de medida, contudo, não é a melhor forma de gestão para um hemocentro, pois a demanda existente é de produtos hemoterápicos e não bolsas de sangue total.

A bolsa de sangue coletada passa por um processamento e pode resultar em mais de um produto de um mesmo tipo sanguíneo. Por meio da diferenciação e tratamento da demanda de cada produto hemoterápico, é possível quantificar metas mais realistas, focadas nas necessidades reais de cada um dos produtos.

Neste sentido, este trabalho constatou a necessidade de um controle mais efetivo dos níveis de estoques nos bancos de sangue brasileiros para evitar desperdício e falta de produtos. Não foi evidenciado um modelo que se aplique a todos os produtos derivados do sangue, sendo necessário utilizar modelos específicos para cada produto.

De modo geral, a demanda prevista correspondeu aos níveis de estoques estabelecidos, respeitando o nível de estoque máximo. Contudo, foram obsevados casos em que a demanda prevista extrapolou esse limite, principalmente para o concentrado de plaquetas, devido à não adequação do modelo de previsão de demanda adotado no estudo aos dados coletados. 
Ao validar o modelo de inventário proposto segundo a demanda prevista para os próximos dois anos, constatou-se que, de modo geral, a demanda projetada tem seus pontos de máximo muito abaixo do nível máximo de estoque. Isso sugere que os níveis mínimos de estoque estão bem dimensionados. Alguns casos mostraram que a demanda prevista permeava valores próximos de estoque mínimo e de segurança.

Os valores de demanda e estoque previstos devem ser constantemente atualizados e conferidos com o gestor do hemocentro a fim de realizar uma melhor administração dos recursos e direcionamento das campanhas de coletas de sangue, observando sempre o componente sazonalidade.

Todas essas ações proporcionarão uma diminuição do descarte das bolsas de sangue, pois coletas desnecessárias deixarão de ser realizadas, da mesma forma que a escassez dos produtos será evitada respeitando-se os níveis de estoques definidos. Destaca-se ainda que este trabalho demonstra a importância da aplicação das ferramentas tradicionalmente utilizadas na indústria para salvar vidas.

A próxima etapa da pesquisa se concentrará no desenvolvimento de uma plataforma integrada de coleta de dados. Estes dados servirão de base para que os algoritmos sejam implementados de forma a gerar as necessidades de estoque futuro por tipo de produto.

\section{REFERÊNCIAS}

AGÊNCIA NACIONAL DE VIGILÂNCIA SANITÁRIA. Hemovigilância: manual técnico para investigação das reações transfusionais imediatas e tardias não infecciosas. Brasília: Anvisa, 2007.

BALOGH, M. B. FEHRENBACH, M. J. Anatomia, histologia e embriologia dos dentes e das estruturas orofaciais. 2 ed. São Paulo: Manole, 2008.

BELIEN, J. e FORCÉ, H. Supply Chain Management of blood products: a literature review. European Journal of Operational Research, v. 217, p. 1-16, 2012.

BEMESTAR. Quase $\mathbf{9 0 \%}$ da população brasileira tem sangue dos tipos A ou $\mathbf{O}$. Disponível em: <http://g1.globo.com/bemestar/noticia/2011/10/quase-90-daopulacao-brasileira-tem-sangue-dos-tipos-e-o.html>. Acesso em: 17 ago. 2012.

BUSS, D. Sangue: fluido da vida, parte 5. 1. ed. São Paulo: Sala Comunicações, 2005. 
CARMO, B.B.T; PONTES, H.L.J; ALBERTIN, M.R.; NETO, J.F.B; DUTRA, N.G.S; Avaliação da demanda por biodiesel em função de um modelo de previsão de demanda por diesel. Revista Produção Online, v.9, n.2, p. 511-535, 2009.

CORRÊA, H. L. CORRÊA, C. A. Administração de produção e operações: manufatura e serviços: uma abordagem estratégica. 2 ed. São Paulo: Atlas, 2008.

FOGLIATTO, F. S., RIBEIRO, J. L. B., WERNER, L., LEMOS, F. O. e BRUM, M. P. Previsão de demanda por energia elétrica: método e aplicação. Revista Produção Online, v 5, n.4, 2005.

GREINACHER, A., FENDRICH, K., ALPEN, U. e HOFFMANN, W. Impact of demographic changes on the blood supply: mecklenburg-West Pomerania as a model region for Europe. Transfusion, v. 47, n.3, p. 395-401, 2007.

GOMES, E. F. P. e GONÇALVEZ, T. T. Clínica médica, volume 3: doenças hematológicas, oncologia, doenças renais e geniturinárias. 1 ed. São Paulo: Manole, 2009.

JORD, L. B. Genética médica. 3. ed. Rio de Janeiro: Elsevier, 2004.

KRAJEWSKI, L. J. RITZMAN, L., MALHOTRA, M. Administração de produção e operações. 8 ed. São Paulo: Person Prentice Hall, 2009.

LEOPRABHU, E. PRAKASH, S. S. VIVEK, I. DEEPAN, P. RANGANATHAN, R. Inventory management for blood banks. Coimbatore Institute of Tecnology. 20062010.

LOPES, A. C. Diagnóstico e tratamento, volume 2. 1 ed. São Paulo: Manole, 2006.

LOPES, F. O. Metodologia para seleção de métodos para previsão de demanda. Dissertação de Mestrado. Programa de Pós Graduação em Engenharia de Produção, Universidade Federal do Rio Grande do Sul, Porto Alegre, 2006.

LUSTOSA, L. et al. Planejamento e controle da produção. 4. ed. Rio de Janeiro: Elsevier, 2008.

MARTINS, P. G. e LAUGENI, F. P. Administração da produção. 2. ed. São Paulo: Saraiva, 2005.

MINISTÉRIO DA SAÚDE. SECRETARIA DE ATENÇÃO À SAÚDE. CoordenaçãoGeral de Sangue e Hemoderivados. Caderno de informação: sangue e hemoderivados, produção hemoterápica. 4 ed. Brasília: Ministério da Saúde, 2011.

. Departamento de Atenção Especializada. Guia para o uso de

hemocomponentes. 1 ed. Brasília: Editora do Ministério da Saúde, 2009.

Revista Produção Online, Florianópolis, SC, v.14, n. 1, p. 264-293, jan./mar. 2014. 
MINISTÉRIO DA SAÚDE. Portaria 1.353 de 13 de junho de 2011. Disponível em http://portal.saude.gov.br/portal/arquivos/pdf/portaria_1353_140611.pdf. Acesso em: 20 jan. 2013.

MOREIRA, D. A. Administração da produção e operações. 2 ed. São Paulo: Cengage Learning, 2011.

PELLEGRINI, F. R. Metodologia para implementação de sistemas de previsão de demanda. Dissertação de Mestrado. Programa de Pós Graduação em Engenharia de Produção, Universidade Federal do Rio Grande do Sul, Porto Alegre, 2000.

ROCHE, J. K. e STENGLE, J. M. Open-heart surgery and the demand for blood. Journal of the American Medical Association, v. 225, n.12, p.1516-1521, 1973.

SALGADO FILHO, A. P., SEGATTO, M., CALIA, R. C., FIOROTTO, J. A., BERTON, L. T. A tecnologia da informação como suporte ao ajuste da previsão de demanda: um estudo de caso em uma empresa de bebidas carbonatadas. Revista Produção Online, v 10, n.3, 2010.

SCHIMIDT, P. J. Blood and disaster: supply and demand. New England Journal of Medicine, v. 346, n. 8, p. 617-620, 2002.

SEVERINO, A. J. Metodologia do trabalho científico. 23. ed. atual. São Paulo: Cortez, 2007.

SILVA, E. L.; MENEZES, E. M. Metodologia da pesquisa e elaboração de dissertação. 4. Ed. rev. Atualizada. Florianópolis: UFSC, 2005.

SLACK, N. CHAMBERS, S. JOHNSTON, R. Administração da produção. 3 ed. São Paulo: Atlas, 2009.

THIBOBEAU, Gary A. PATTON, Kevin T. Estrutura e funções do corpo humano. 11. ed. São Paulo: Manole, 2002.

TUBINO, D. F. Planejamento e controle da produção: teoria e prática. São Paulo: Atlas, 2007.

WERNER, L e RIBEIRO, J. L. D. Modelo composto para prever demanda através da integração de previsões. Revista Produção, v.16 n.3. São Paulo, 2006.

WILD, Tony. Best Practice in Inventory Management. 2 ed. Woburn: Elsevier Science, 2002.

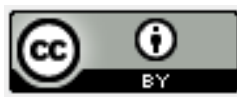

Artigo recebido em 09/05/2013 e aceito para publicação em 13/02/2014.

DOI: http://dx.doi.org/10.14488/1676-1901.v14.i1.1594

Revista Produção Online, Florianópolis, SC, v.14, n. 1, p. 264-293, jan./mar. 2014. 